\title{
Minor psychiatric disorders among nursing workers - is there an association with current or former night work?
}

\author{
Thiago Bernardes Diniz , Aline Silva-Costa, Rosane Harter Griep and Lúcia Rotenberg \\ Laboratory of Health and Environment Education, Oswaldo Cruz Institute, Oswaldo Cruz Foundation Avenida \\ Brasil, 4365, Manguinhos, CEP 21045-900 Rio de Janeiro, RJ, Brazil.
}

\begin{abstract}
We aimed at analyzing whether Minor Psychiatric Disorders (MPD) is associated to night work either currently or in the past. A cross-sectional study was conducted at three public hospitals in Brazil, with female nursing workers. Data collection $(\mathrm{N}=1,134)$ was based on a comprehensive questionnaire that included the self-reported questionnaire (SRQ-20) for screening of MPD. Former night workers were subdivided into three groups according to their reasons for leaving night work: (i) directly related to work, (ii) related to better reconcile with studies or another job, and (iii) related to health, sleep, fatigue or stress. Binomial logistic regression was performed, with adjustment for potential confounders. A dose response gradient was observed between current night work and MPD $(\mathrm{OR}=1.5 ; 95 \% \mathrm{CI}: 1.1-2.2$ and $\mathrm{OR}=2.1 ; 95 \% \mathrm{CI}$ : $1.5-3.1$ for those who worked up to five nights and six or more nights per 2-week span, respectively). Potential detrimental effects of night work were confirmed. The association between working at night and MPD was not restricted to current night workers as workers who left night work for health/fatigue/sleep/strain also showed higher chances of reporting MPD (OR=1.8;95\%CI:1.14-2.90). Results contribute to the scientific debate on the impact of night work on health and wellbeing.
\end{abstract}

Keywords: Night Work, Mental Health, Nursing, Work Organization, SQR-20

\section{Introduction}

The mental strain at work is regarded as the consumption of the body and the psychic potential associated with the work process [5]. The author of this description is inscribed in the field of Mental Health and Work, which seeks to understand the interrelationships between occupational factors "targeted" by epidemiological studies, subjectivity and social aspects of life that take place in work contexts [6]. It is an interdisciplinary field that incorporates situations ranging from malaise to the psychiatric disorders, including clinical pathologies related to the mental area (such as those resulting from contact with toxic agents), aspects of mental fatigue and / or physical as well as frameworks which violate the workers' identity in their values and beliefs, as presented by [17].
In the relationships between work and mental health we highlight the organization of work, whose key aspects - hierarchical structure of employees, degree of autonomy, interpersonal and intergroup relations, division of activities and temporal structure of work - should be investigated in their interarticulations and in a contextualized way $[4,6]$.

The present study addresses the temporal structure of work - shift work - under the assumption that working at night means contradicting the biological temporal organization and patterns of social life, where activities are concentrated during the daytime. The effects of night work include aspects related to bio-psychosocial maladjustment of circadian rhythms and changes in lifestyle and family life $[11,24]$ and may lead to gastrointestinal and cardiovascular disorders, among others [12]. Social-familial problems add up to sleep deprivation, with signs of

\footnotetext{
*Corresponding author. Email: tbdiniz@ioc.fiocruz.br
} 
irritability, fatigue and mood changes, which in turn, also interact with mental health [26].

Case studies with qualitative approaches describe situations of chronic fatigue and emotional crises in workers exposed, in the past or presently, to work in shifts associated with the intense pace, inadequate pauses and / or excessive overtime [4, 17]. It is noteworthy in these studies, the interrelationship between varied symptoms such as the experience of accumulated fatigue, sleep disturbances, body aches, loss of appetite, irritability, depression and headaches.

Yet the epidemiological studies analyze constructs linked to the psychic sphere from scales or issues such as "severe emotional problems" [22], "psychological ill-health" [13] or "mental distress" [3]. In the context of epidemiological studies, the self-report questionnaire (SRQ-20) has been recommended by the World Health Organization for screening non-psychotic mental disorders, usually referred to the Minor Psychiatric Disorders [MPD] [29, 27].

This study aims to contribute to this scientific debate through an epidemiological investigation on minor psychic disorders among nursing workers. In Brazilian hospitals, night work is usually organized in long (12-h) shifts, with no consecutive working nights, thus favoring the holding of more than one job. The increasing time spent working [16] has potential repercussions in workers' sleep and mental health [8]. Our aim is to investigate whether minor psychic disorders among nursing workers is related to night work either currently or in the past.

\section{Methods}

In order to create a new A cross-sectional study was conducted at three public hospital units in Rio de Janeiro, Brazil. Data collection took place from June 2005 to March 2006. The eligible group, comprising all nursing teams engaged in assistance to patients (nurses, nursing aides/assistants), were invited to participate. The procedures used for contacting workers were in compliance with ethical aspects to conduct research with human subjects. The project was approved by the Ethics Committee of the Oswaldo Cruz Foundation, and by the Ethics Committee of each studied hospital; it was also approved by the Brazilian National Committee of Ethics, under the number CONEP-10228.

Data collection was based on a comprehensive questionnaire that included information on sociodemographics, lifestyle and health-related behaviors and work variables (including current and past work schedules). The questionnaire also included scales and questions on physical and mental health, including the SRQ-20, which was used for screening of minor psychiatric disorders [14].

The instrument considered the complexity involved in defining work hours for those workers, due to the high rate of them who are engaged on two jobs at hospitals. Therefore, current night workers were invited to recall the nights they had worked during two weeks preceding data collection, considering all jobs [18]. A sequence of procedures was adopted to classify workers according to their current and past work hours [19]. Firstly, four groups were defined (i) those who had never worked at night (day workers exclusively), (ii) day workers who had worked at night in the past, i.e., former night workers, (iii) those who worked up to five nights per 2-week span, and (iv) those who worked six or more nights per 2-week span. Secondly, former night workers were asked for their main reason for leaving night work so as to better describe this group, which was subdivided into three subgroups: (i) reasons directly related to work (retiring, changes in the hospital sector), (ii) related to better reconcile with studies or another job, and (iii) related to health, sleep, fatigue or stress.

Minor psychic disorders were evaluated by means of the Self-Report Questionnaire (SRQ-20), a 20item questionnaire that allows the screening of minor psychiatric disorders (depression, anxiety, somatoform disorders and neurasthenia), more than to establish diagnostic categories of mental health [14]. Seven items answered positively was established as the cut-off, according to validation considering specificity and sensibility among occupational groups [15].

The association between work schedules and minor psychiatric disorders was tested through binomial logistic regression, with results presented as Odds Ratios and 95\% confidence intervals. The following variables were tested as confounders for analysis: age, marital status, children, family income, race, education degree, body mass index (BMI) smoking, alcohol consumption, physical activity, professional category, number of jobs, type of employment (permanent job versus temporary or outsourced job), and psychosocial factors at work: demand-control ratio and effort-reward imbalance. Potential confounders were screened by bi-variant Chi-square tests. Those with at least a minimum association $(\mathrm{p}<0.20)$ were selected for inclusion in the models. Those with no experience on night work (day workers exclusively) were considered as the reference group. Descriptive 
analyzes of sociodemography as well as variables related to work and lifestyle were based on chisquare tests (significance at 0.05 ). Statistical analyzes were performed using the SPSS software, version 18.0.

\section{Results}

The sample consisted of 1,134 female nursing workers. The more frequent work schedules adopted at the hospitals were: (i) night shift: 19:00-07:00 h, followed by $60 \mathrm{~h}$ or $36 \mathrm{~h}$ off, (ii) day shift (07:0019:00 h), followed by 60 or $36 \mathrm{~h}$ off, (iii) 24 -h shift: 07:00-07:00 h, followed by $120 \mathrm{~h}$ off, (iv) day work at week days.

Among the total samples, 281 had never worked at night (day workers exclusively), 312 were former night workers, 289 worked up to five nights per 2week span, and 252 worked six or more nights per 2week span. Considering reasons for quitting night work, the studied group encompassed 126 workers who alleged reasons directly related to work (retiring, changes in the hospital sector), 57 reported reasons related to better reconcile with studies or another job, and 129 reported reasons related to health, sleep or fatigue $(n=129)$.
Table 1 describes the main features of the studied groups. A high proportion of current night workers (at least $50 \%$ ) are engaged in two or more jobs. Compared to the group that has never worked at night, workers who currently work six or more nights per 2-week span are younger, have longer professional work hours, and show a higher proportion who are single, and with college degree. In general, former night workers are older, and show shorter professional work hours. The prevalence of MPD in the total population was $33.7 \%$, varying from $23.8 \%$ among those who left night work for reasons associated with work (e.g, retirement, change of sector) to $45.2 \%$ among currently working six or more nights per fortnight (Table 1).

A dose response gradient was observed between current night work and MPD, as shown by the odds ratios: $\mathrm{OR}=1.5$; and $\mathrm{OR}=2.1$ for those who work up to five nights per 2-week span and those who work six or more nights per 2-week span, respectively (Table 2). Day workers who left night work for health reasons showed a higher chance of reporting MPD, compared to day workers with no night work experience. 
Table 1

Description of sample $(\mathrm{n}=1.134)$ as to sociodemographic and variables related to lifestyle and work.

\begin{tabular}{|c|c|c|c|c|c|c|c|}
\hline \multirow{3}{*}{$\begin{array}{r}\text { Variable } \\
\text { Age (mean; sd) }\end{array}$} & \multirow{3}{*}{$\begin{array}{r}\begin{array}{r}\text { Day work } \\
\text { exclusively }\end{array} \\
\\
37.0 ; 13.6\end{array}$} & \multicolumn{2}{|c|}{ Current night work } & \multicolumn{3}{|c|}{ Former night work } & \multirow{3}{*}{$\begin{array}{c}\text { p-value } \\
<0.001\end{array}$} \\
\hline & & \multirow{2}{*}{$\begin{array}{c}\begin{array}{c}5 \text { nights/2 } \\
\text { week-span }\end{array} \\
43.2 ; 11.1\end{array}$} & \multirow{2}{*}{$\begin{array}{c}\begin{array}{c}6 \text { or more } \\
\text { nights/2 week- } \\
\text { span }\end{array} \\
31.4 ; 10.3\end{array}$} & \multirow{2}{*}{$\begin{array}{c}\text { Work } \\
46.1 ; 11.8\end{array}$} & \multirow{2}{*}{$\begin{array}{c}\begin{array}{c}\text { Concilia- } \\
\text { tion with } \\
\text { other job or } \\
\text { study }\end{array} \\
47.4 ; 9.5\end{array}$} & \multirow{2}{*}{$\begin{array}{c}\text { Health } \\
47.4 ; 9,6\end{array}$} & \\
\hline & & & & & & & \\
\hline Marital status (\%) & & & & & & & 0.009 \\
\hline Married / live with a partner & 43.2 & 48.8 & 37.7 & 40.0 & 52.6 & 41.1 & \\
\hline without wedlock & 56.8 & 51.2 & 66.3 & 60.0 & 47.4 & 58.9 & \\
\hline Overweight/obese (\%) & 38.9 & 53.6 & 35.9 & 53.3 & 44.4 & 52.8 & $<0.001$ \\
\hline Smoking habits (\%) & 23,5 & 33.9 & 19.4 & 30.2 & 42.1 & 40.3 & $<0.001$ \\
\hline Physical activity (\%) & 28.5 & 28.0 & 26.2 & 31.0 & 40.4 & 32.6 & 0.338 \\
\hline Education degree $(\%)$ & & & & & & & $<0.001$ \\
\hline Non-college degree & 55.0 & 48.6 & 21.4 & 51.6 & 54.4 & 42.6 & \\
\hline College degree & 45.0 & 51.4 & 78.6 & 48.4 & 45.6 & 57.4 & \\
\hline Family income (\%) & & & & & & & 0.296 \\
\hline Up to US\$ 391 & 64.3 & 66.9 & 57.6 & 61.9 & 69.1 & 63.5 & \\
\hline Above US\$ 391 & 35.7 & 33.1 & 42.4 & 38.1 & 30.9 & 36.5 & \\
\hline Engaged in 2 or more jobs (\%) & 13.5 & 49.8 & 63.1 & 15.9 & 17.5 & 29.5 & $<0.001$ \\
\hline $\begin{array}{l}\text { Weekly professional work hours } \\
\text { (mean; standard deviation) }\end{array}$ & $40.5 ; 12.1$ & $53.4 ; 18.8$ & $62.6 ; 21.5$ & $37.2 ; 13.3$ & $36.9 ; 12.4$ & $37.0 ; 13.8$ & $<0.001$ \\
\hline $\begin{array}{l}\text { Weekly domestic work hours } \\
\text { (mean; standard deviation) }\end{array}$ & $15.6 ; 14.0$ & $19.1 ; 17.7$ & $11.2 ; 13.5$ & $17.1 ; 12.8$ & $18.5 ; 11.8$ & $18.2 ; 14.1$ & $<0.001$ \\
\hline Minor psychic disorders $(\%)$ & 26.7 & 33.9 & 45.2 & 23.8 & 29.8 & 37.2 & $<0.001$ \\
\hline
\end{tabular}

Table 2

Crude and adjusted odds ratio for the association between current and past work hours and minor psychic disorders among nursing workers $(\mathrm{N}=1,134)$.

\begin{tabular}{|c|c|c|c|c|}
\hline & Current and past work hours & $\mathbf{N}$ & $\begin{array}{l}\text { Crude OR } \\
\text { (CI 95\%) }\end{array}$ & $\begin{array}{l}\text { Adjusted OR* } \\
\text { (CI 95\%) }\end{array}$ \\
\hline \multirow{3}{*}{ 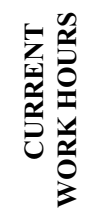 } & Day workers exclusively (reference group) & 281 & 1.00 & 1.00 \\
\hline & $\begin{array}{l}\text { Night workers } \\
\text { Up to } 5 \text { nights } / 2 \text { week-span }\end{array}$ & 289 & $1.41(0.98-2.02)$ & $1.53(2.06-2.22)$ \\
\hline & $\begin{array}{l}\text { Night workers } \\
\text { With } 6 \text { or more nights } / 2 \text { week-span }\end{array}$ & 252 & $2.26(1.57-3.25)$ & $2.12(1.47-3.08)$ \\
\hline \multirow{3}{*}{ 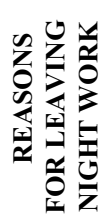 } & $\begin{array}{l}\text { Former night workers }- \text { reasons related to } \\
\text { work (retiring, changes in the hospital sector) }\end{array}$ & 126 & $0.86(0.53-1.40)$ & $0.96(0.58-1.58)$ \\
\hline & $\begin{array}{l}\text { Former night workers - reasons related to bet- } \\
\text { ter reconcile with studies or another job }\end{array}$ & 57 & $1.16(0.62-2.16)$ & $1.35(0.71-2.57)$ \\
\hline & $\begin{array}{l}\text { Former night workers - reasons related to } \\
\text { health, sleep, fatigue or stress }\end{array}$ & 129 & $1.63(1.05-2.55)$ & $1.82(1.14-2.90)$ \\
\hline
\end{tabular}




\section{Discussion}

The dose response gradient observed between the number of working nights and MPD (higher OR for those who worked more nights than the OR for those who worked less nights: $\mathrm{OR}=2.1$ versus $\mathrm{OR}=1.5$ ) points to detrimental effects of night work on mental health. As these professionals work 12-hour shifts, the long duration of work hours is added to the organic and social effects known to be associated with night work [12], a combination that can enhance the consequences of night work. Such characteristics of work organization may be experienced by workers as an excess of work demands, which tends to affect negatively, cognition (reducing the ability to concentrate), emotional stability (in terms of anxiety, depression or mental fatigue) and physiology through neuroendocrine and immune system reactions [25]. Therefore, working at night in the studied group seems to be linked to a mental strain in which the employee submits to the demands of the work process - in this case related to working time - that can consume the body and psychic potential $[1,6]$.

The range of effects of night work described in the literature can be exemplified by the material obtained in interviews with nursing workers in one of the hospitals studied [23]. There are workers who reported "not being used" to work at night, even after ten years of nocturnal activity, with the explanation that the "biological clock" does not adapt to this situation. Already the mentioning of shift workers as "unusual" people, since their schedules are "mismatched" from family and neighbours, expresses an effect of work in social life [23]. Thus, the organic aspects, the symptoms related to anxiety and depression as well as those linked to the cognitive area or reduction of energy included in the SRQ-20 [23], give biopsychosocial plausibility to the association between shift work and MPD.

If these results point to shift work as harmful in terms of MPD manifestation, on the other hand, the fact that the association with the MPD is expressed only in a group of former night workers highlights the role of individual differences in the relations between work and health [21]. One should recognize aspects of the individual, their personality and their historical trajectory of life and work in analysing the work-mental sphere interface [4]. In fact, the literature indicates an estimated $20 \%$ of workers who leave shift work in short time [21]. Among those who remain, there are different degrees of intolerance, according to age, physiological and social aspects such as marital status, number and age of children and/or factors related to the work itself, as the duration and intensity of exposure to this work schedule [9]. In this sense, the differences between the groups of former night workers may reflect different degrees of tolerance to shift work. These results remit to the recommendation by [20] on the differentiation between different groups of former night workers, as it prevents the underestimation of real problems of the relevant group of workers who left night work for health reasons.

In the context of work-health relationships, the permanence in night shifts, due to some advantageous features related to income or conciliation with diurnal domestic work, amongst others [23] would lead to the worker's mental strain, resulting from an unequal correlation of forces [6] in that workers have to deal with harmful aspects of work in health and wellbeing.

It is worth noting the high prevalence of MPD in the studied group (around a third of workers), an amount equal to that reported by [28] as regards nursing workers at a public hospital in Salvador, another Brazilian city. These values are higher than the one described by [2] on nursing workers, probably due to differences in the cut-off for defining cases. The high proportion of workers with psychic disorders among those who work six nights or more per fortnight is of particularly concern, considering they are relatively young, with mean age around 30 years old. Our data on the prevalence of MPD is likely to be related to specificities of Brazilian nursing workers as regards work organization, particularly related to the long duration of professional work hours due to engagement on two or, even, three jobs on nursing assistance [7]. Low income combined to work schedules without consecutive working nights contribute to this situation.

Among the limitations of this study are its crosssectional design and critique to the epidemiological approach for the study of mental health at work as it does not allow analysing the disease development process [6]. In spite of these limitations, the results point to possible risk factors for mental health related to work schedules that should be considered in the analysis of work organization and its impact on health. In the context of work schedules here analysed, the empowerment of the nursing profession with a guarantee of higher wages would help workers cope with the inevitable problems arising from night work. This would certainly benefit both employees and the quality of care. 


\section{References}

[1] A.C. Laurell, M. Noriega, Processo de produção de saúde: trabalho e desgaste operário, Hucitec, São Paulo, 1989.

[2] A.L.C. Kirchhof, T.S.B.S Magnago, S. Camponogara, R.H Griep, J.P. Tavares, F.C. Prestes et al., Condições de trabalho e características sociodemográficas relacionadas à presença de distúrbios psíquicos menores em trabalhadores de enfermagem, Texto Contexto Enferm 18 (2009), 215-23.

[3] C.H. Ljoså, R. Tyssen, B. Lau, Mental distress among shift workers in Norwegian offshore petroleum industry - relative influence of individual and psychosocial work factors, Scand J Work Environ Health 27 (2011).

[4] E. Seligmann-Silva, A Inter-relação Trabalho-saúde Mental: um Estudo de Caso, ERA - Revista de Administração de Empresas 32 (1992)

[5] E. Seligmann-Silva, Desgaste Mental no Trabalho Dominado, Cortez, Rio de Janeiro, 1994

[6] E. Seligmann-Silva, Psicopatologia e Saúde Mental no Trabalho, in: Psicopatologia do Trabalho, René Mendes, Org.., Atheneu, Rio de Janeiro, 2003, pp. 1141-1182.

[7] F. Ribeiro-Silva, L. Rotenberg, R.E. Soares, J. Pessanha, F.L. Ferreira, P. Oliveira, A. Silva-Costa, A.A. Benedito-Silva, Sleep on the job partially compensates for sleep loss in nightshift nurses, Chronobiol Int 23 (2006), 1389-99.

[8] F.M. Fischer, F.N. Borges, L. Rotenberg, M.R. Latorre, N.S. Soares, P.L. Rosa, L.R. Teixeira, R. Nagai, J. Steluti, P. Landsbergis, Work ability of health care shift workers: What matters?, Chronobiol Int.23 (2006),1165-79.

[9] G Costa, The impact of shift and night work on health, Applied Ergonomics 27 (1996), 9-16.

[10] G. Costa, S. Sartori, Ageing, working hours and work ability. Ergonomics 50 (2007), 1914-30.

[11] G. Costa, Shift work and occupational medicine: an overview, Occupational Medicine 53 (2003), 83- 88.

[12] G. Costa, Shift Work and Health: Current Problems and Preventive Actions, Safety Health Work 1 (2010), 112-123.

[13] J. Barton, E. Spelten, P. Totterdell, L. Smith, S. Folkard, Is there an optimum number of night shifts? Relationship between sleep, health and well-being. Work Stress 9 (1995), 109-123.

[14] J. Mari, P.A. Willians, A validity study of a psychiatric screening questionnaire (SRQ-20) in primary care in the city of São Paulo, Br J Psychiatry148 (1986),23-6.

[15] K.O.B. Santos, Estresse Ocupacional e Saúde Mental: desempenho de instrumentos de avaliação em populações de trabalhadores na Bahia-Brasil, Dissertation, Universidade de Feira de Santana, 2006.

[16] L.F. Portela, L. Rotenberg, W. Waissmann, Health, sleep and lack of time: relations to domestic and paid work in nurses, Rev. Saúde Pública 39 (2005), 802-808.

[17] L.E. Rocha, M.L. Batista, M.G.V. Mendonça, Saúde Mental e Trabalho: contribuição para o reconhecimento da relação entre situação de trabalho e distúrbios psíquicos, Revista Brasileira de Saúde Ocupacional 26 (2001) 81-98.

[18] L. Roterberg, L.F. Portela, B. Banks, R.H. Griep, F.M. Fischer, P. Landsbergis, A gender approach to work ability and its relationship to professional and domestic work hours among nursing personnel, Applied Ergonomics 39 (2008), 646-652.

[19] L. Rotenberg, A. Silva-Costa, T.B. Diniz, R.H. Griep, Longterm deleterious effects of night work on sleep, Sleep Science, 2011.

[20] M. Frese, K. Okonek, Reasons to leave shiftworkand psychological and psychosomatic complaints of former shiftworkers, Journal of Applied Psychology 69 (1984), 509-514.

[21] M. Koller. Health risks related to shiftwork. An example of time contingent effects of long-term stress, Int Arch Occup Environ Health 53 (1983), 59-75.

[22] N.P. Gordon, P.D. Cleary, C.E. Parker, C.A. Czeisler. The prevalence and health impact of shiftwork, Am J Public Health 76 (1986), 1225-1228.

[23] R.E.S. Soares, Tempo, trabalho e modo de vida. Estudo de caso entre profissionais da enfermagem, Dissertation, Universidade Federal Fluminense, 2005.

[24] S. Folkard, Do permanent night workers show circadian adjustment? A review based on the endogenous melatonin rhythm, Chronobiol Int. 25 (2008), 215-24.

[25] S.B. Levy, D.H. Wegman, Occupational Health: Recognizing and Preventing Work-Related Disease, Little, Brown and Company, Boston/Toronto, 1988.

[26] T. Akerstedt, Psychosocial stress and impaired sleep, Scandinavian Journal of Work Environment \& Health 32 (2006), 493-501.

[27] T. Harpham, M. Reichenheim, R. Oser, et al. Measuring mental health in a cost-effective manner, Health Policy Plan 18 (2003), 344-349.

[28] T.M. Araújo, E. Aquino, G. Menezes, C. O. Santos, L. Aguiar, Aspectos psicossociais do trabalho e distúrbios psíquicos entre trabalhadoras de enfermagem, Revista de Saúde Pública 37 (2003), 424-43.

[29] WHO. User's guide to the Self-Reporting Questionnaire (SRQ). Geneva: World Health Organization, 1994. 